\title{
HERANÇA DE COLORAÇÃO DE BULBOS EM CEBOLA (Allium cepa L.) COM RESISTÊNCIA A Colletotrichum gloeosporioides
}

\author{
A.I.I. CARDOSO; P.T. DELLA VECCHIA; ${ }^{2}$ L.P. FARIA ${ }^{2}$ \\ ${ }_{2}^{1}$ Pós-Graduando do Depto. de Genética-ESALQ/USP \\ ${ }^{2}$ AGROFLORA S/A. C.P. 427, CEP: 12900-000, Bragança Paulısta-SP.
}

\begin{abstract}
RESUMO: O objetivo deste trabalho fol determinar a herança de coloração de bulbos de cebola a partir do cruzamento de bulbos brancos com resistência a Colletotrichum gloeosporioides (Mal de 7 voltas) segregantes da população Roxa do Barrein com bulbos amarelos de linhagens endogâmicas obtidas das variedades Super Precoce e Pira Ouro. Para tal obtiveram-se as geraçōes F1 e F2 entre (Super Precoce x Barreiro "Branca") e entre (Pira Ouro x Barreiro "Branca"). Nas geraçōes F1 obtiveram-se apenas bulbos roxos, enquanto que nas geraçōes $F 2$ obtiveram-se uma segregação para bulbos roxos, brancos e amarelos numa proporção aproximada de 9:4:3, o que permitiu concluir que a herança, para estes cruzamentos, foi devida a 2 pares de genes contrastantes nas populaçōes progenitoras, cujos genótipos, com base na literatura, sāo: li cc RR (Barreiro Branca) e ii CC rr (linhagens de Super Precoce e de Pira Ouro). Conclui-se, também, que é possível, a partir destes cruzamentos, obter uma variedade ou linhagem com resistência a $C$. gloeosporioides somente com bulbos amarelos ou com bulbos brancos com genótipo homozigoto recessivo para todos os genes, que quando cruzada com outra amarela pode-se obter uma geraçāo $F 1$ com bulbos amarelos e com resistência a $C$. gloeosporioides. Descritores: cebola ( $A$ llium cepa), coloração de bulbos, mal-de-7-voltas
\end{abstract}

\section{INHERITANCE OF BULB COLOR IN ONION (allium cepa l.) RESISTANT TO Colletotrichum gloeosporioides}

\begin{abstract}
The inheritance of onion bulb color was studied utilizing white bulbs resistant to Colletotrichum gloeosporioides that segregated from the population 'Roxa do Barreiro' and two inbred lines with yellow bulbs originated from 'Super Precoce' and 'Pira Ouro' cultivars. The white bulbs and the inbred lines were crossed to obtain the F1 and F2 generations (yellow $x$ white). Both $F 1$ generations were of red bulbs and in the $F 2$ generation there were segregations to red, white and yellow bulbs in a proportion of 9:4:3, respectively. It was concluded that the inheritance of bulb color in these crosses is controlled by two contrasting genes in the parental (if cc $\mathrm{RR}=$ white bulbs, if $\mathrm{CC}$ rr $=$ yellow bulbs) material). It is probably possible to obtain a new variety or inbred line resistant to $C$. gloeosporioides with yellow bulbs or white bübs, which, when crossed with a yellow line, will result in a yellow bulb $F 1$ resistant to this pathogen. Key Words: onion (Alium cepa), bulb color, Colletoirichum gloeosporioides
\end{abstract}

\section{INTRODUÇÃO}

Colletotrichum gloeosporioides Penz [sensu ARX, 1957] é o agente causal da doença "mal de sete voltas" em cebola, de ocorrência endémica nas principais áreas produtoras desta cultura no Brasil. $\mathrm{O}$ uso de cultivares resistentes é o método de controle mais econômico e eficiente, principalmente porque o controle quimico é ineficiente quando as condições são favoráveis ao patógeno, além de onerar o custo de produção.

Para que seja possivel o melhoramento visando resistência genética é necessário ter-se um material como fonte de resistência, um outro adaptado, ao qual se deseja incorporar esta resistência, e conhecer-se o modo de herança da reação do hospedeiro

Sci. agric., Piracicaba, 52 (2): 384 -386 , mai./ago. 1995
A cebola Roxa do Barreiro é uma fonte de resistência e a herança desta resistência, com base no cruzamento Baia $x$ Barreiro, é de natureza poligênica e aditiva (SILVA, 1976). A geração F1 entre esta cebola Roxa do Barreiro e as cebolas do tipo Baia, apesar de apresentar bom nivel de resistência, tem bulbos roxos e a cor ideal para o mercado das Baias, que é o tipo preferido no mercado de São Paulo, é a amarela. Porém a população Barreiro segrega, quando autofecundada, para bulbos brancos (ZIMMERMAN, 1973) e não há relatos sobre a herança da coloração de bulbos a partir do cruzamento entre bulbos brancos da população Barreiro com bulbos amarelos de cultivares derivadas de Baia. Com o objetivo de se obter informações a respeito da herança da coloração de bulbos a partir deste cru. zamento, visando auxiliar os trabalhos de melhora- 
mento de obtenção de cultivares ou híbridos F1, realizou-se este trabalho.

\section{MATERLAL E METODOS}

$O$ experimento foi conduzido na Estação Experimental da AGROFLORA S/A em Bragança Paulista-SP na safra de 1993. Inicialmente foram utilizados os seguintes materiais para a realização deste estudo: 10 bulbos brancos de cebola Barreiro com resistência a $C$. gloeosporioides, obtidos em produtores da região de Belo Horizonte-MG, uma linhagem endogâmica obtida da população Super Precoce somente com bulbos amarelos e outra linhagem endogâmica obtida da população Pira Ouro também somente com bulbos amarelos, sendo que estes materiais serão denominados de BB (Barreiro Branca), SPA (Super Precoce Amarela) e POA (Pira Ouro Amarela)

Utilizando-se estes materiais obtiveram-se as gerações $F 1$ e $F 2$ a partir de 2 cruzamentos, (SPA $x$ $\mathrm{BB})$ e (POA x BB)

As gerações $F 1$ foram obtidas na safra de 1989 utilizando-se como progenitor masculino a $\mathrm{BB}$ e femınıno plantas macho estéreis de SPA e POA e as gerações F2 na safra de 1991 intercruzando-se plan- tas de cada geração F1 entre si. Na safra 1993 foram semeadas todas estas 4 gerações, sendo utilizados um maior número de plantas das gerações $F 2$ visto que estas são as gerações que se esperava obter segregação.

A avaliação foi realizada na colheita dos bulbos separando-se e contando-se os bulbos de acordo com a cor (branco, amarelo e roxo). A partir destes dados foram efetuadas as análises pelo teste do Quiquadrado $\left(\mathrm{X}^{2}\right)$, conforme SNEDECOR \& COCHRAN (1976), para se determinar a herança da coloração de bulbos nestes materiais.

\section{RESULTADOS E DISCUSSÃO}

Os resultados da contagem de bulbos por coloração estão apresentados na TABELA 1. Nas gerações Fl só foram obtidos bulbos roxos apesar de nenhum dos progenitores apresentarem bulbos com esta coloração. Já nas gerações F2 obteve-se segregação para bulbos roxos, brancos e amarelos, numa proporção aproximada de 9:4:3, o que indica uma provável herança genética devido a 2 pares de genes complementares, hipótese confirmada pelo teste do $\mathrm{X}^{2}$ com mais de $99 \%$ de probabilidade nos 2 cruzamentos.

TABELA 1: Número de bulbos por coloração nas gerações $\mathrm{F} 1$ e F2 e teste do $\mathrm{X}^{2}$ para 2 pares de genes complementares.

\begin{tabular}{lccccccll}
\hline \hline & total & \multicolumn{3}{c}{ número de bulbos } & \multicolumn{2}{c}{ relação } & & \\
geração & plantas & roxo & branco & amarelo & esperada & $x^{2}$ & prob & - \\
\hline (SPA x BB) F1 & 45 & 45 & 0 & 0 & $1: 0: 0$ & & & \\
(POA x BB) F1 & 43 & 43 & 0 & 0 & $1: 0: 0$ & & \\
(SPA x BB) F2 & 373 & 196 & 101 & 76 & $9: 4: 3$ & 2,1 & $>99 \%$ \\
(POA x BB) F2 & 212 & 111 & 56 & 45 & $9: 4: 3$ & 1,43 & $>99 \%$ \\
\hline \hline
\end{tabular}

prob $=$ probabilidade

Segundo PIKE (1986) a herança da coloração dos bulbos em cebola é devido a 3 pares de genes que interagem entre si (Ii, Cc, Rr). O gene I, chamado de inibidor, na forma dominante condiciona coloração branca independentemente dos outros 2 pares de genes que só se manifestam quando este gene inibidor se encontra no estado homozigoto recessivo (ii). Satisfeita esta condição o gene $R$ e o gene $C$, ambos na forma dominante, condicionam coloração roxa. Se o gene $\mathrm{R}$ se encontrar na forma homozigota recessiva e o gene $C$ na forma dominante tem-se a coloração amarela, enquanto que se este gene se encontrar no estado homozigoto recessivo (cc) temse bulbos brancos, independentemente do gene $\mathrm{R}$ se encontrar na forma dominante ou recessiva.
A partir destes dados pode-se determinar os genótipos dos materiais estudados. Os bulbos brancos da população Barreiro (BB) apresentam genótipo ii cc RR, e as linhagens endogâmicas com bulbos amarelos (SPA e POA) apresentam genótipo ii CC rr. Assim as gerações F1 são ii $\mathrm{Cc} R r$, ou seja, com bulbos roxos e as gerações $\mathrm{F} 2$ segregam na proporção 9:4:3 para bulbos roxos, brancos c amarelos, respectivamente.

Assim pode-se afirmar que é possivel obterse cultivares com resistência a $C$. gloeosporioides independentemente da cor dos bulbos já que a população BB era composta apenas por bulbos brancos resistentes, mostrando que estas 2 características não devem estar ligadas (bulbos roxos e resistência). 
Também podem ser obtidos híbridos F1 de coloração amarela mesmo a partir de um cruzamento entre um progenitor de bulbos amarelos e outro branco, desde que 0 de bulbos brancos tenha genotipo completamente recessivo (ii, cc, rr). Porém este genótipo provavelmente não é encontrado diretamente na população Barreiro, pois esta não deve ter em seu genoma o gene $r$, na forma recessiva, caso contrário esta populaçăo também segregaria para bulbos amarelos (ii, C, rr) fato que não se tem relato, nem mesmo no trabalho de ZIMMERMAN (1973).

Entretanto deve-se ressaltar que a herança de coloração não é tão simples assim quando se trabaIha com populaços que segregam para bulbos roxos, pois existe uma variação desde o levemente arroxeado até o roxo propriamente dito. Neste trabalho a maioria dos bulbos das gerações F1 são arroxeados, enquanto que os da geração F2 abrangem bulbos de todas as classes desde o levemente arroxeado até o roxo. Como propóe PIKE (1986) isto deve ser devido a ação de diversos genes complementares e aditivos. Porém tem-se observado que também fatores ambientais, provavelmente temperatura, podem influenciar a intensidade da coloração arroxeada, pois quando se cultiva um mesmo lote de cebola Pira Ouro, que segrega bulbos arroxeados, em diferentes locais a proporçãa de bulbos fortemente arroxeados tende a ser maior em con- diçбes ou locais de temperatura mais elevada (CARDOSO, dados não publicados). Por isto estudos complementares são necessários para se esclarecer completamente a herança de coloração de bulbos de cebola.

\section{REFERENCIAS BIBLIOGRÁFICAS}

PIKE, L.M. Onion Breeding. In. BASSET, M. Breeding Vegetalle Crops. Westport: AVI Publishing, 1986. p.357394.

SILVA, N. Resistência em cebola (Allium cepa L.) à Colletotnchum gloeosporiordes. Piracicaba, 1976. (Dissertação) Mestrado - Escola Superior de Agricultura "Luiz de Queiroz", Universidade de São Paulo.

SNEDECOR, G.W; COCHRAN, W.G. Statistical methods. 6 ed., Ames: lowa, 1974. 593p.

ZIMMERMAN, M.J.O. Efeitos da autofecundação na variedade de cebola Barreiro (Allium cepa L.). Piracicaba, 1973. 92p. (Dissertaçăo) Mestrado - Escola Superior de Agricultura "Luiz de Queiroz", Universidade de São Paulo.

Recebido para publicação em 02.09.94

Aceito para publicą̧ão em 04.0595 